
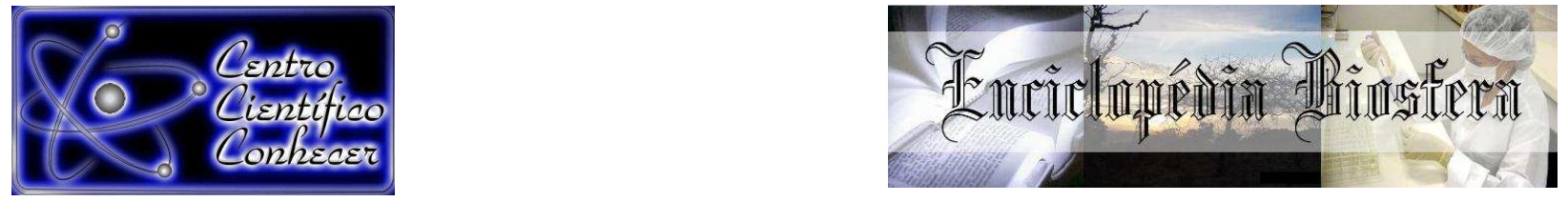

\title{
AVALIAÇÃO DE ELEMENTOS QUÍMICOS ESSENCIAIS E CHUMBO EM TECIDOS BOVINOS NA BAHIA, BRASIL
}

\footnotetext{
Adelmo Ferreira de Santana ${ }^{1}$, Edevaldo da Silva ${ }^{2}$, Zenira Cardoso Vilasboas Viana ${ }^{3}$, Maria das Graças Andrade Korn ${ }^{4}$, Vera Lúcia Câncio Souza Santos ${ }^{5}$
}

1Professor Doutor do Departamento de Produção Animal da Escola de Medicina Veterinária da Universidade Federal da Bahia, Salvador-Brasil.

2 Professor Doutor da Unidade Acadêmica de Ciências Biológicas, Universidade

Federal de Campina Grande, Paraíba-Brasil.

${ }^{3}$ Professora Doutora do Departamento de Biofunção do Instituto de Ciências da

Saúde da Universidade Federal da Bahia, Salvador-Brasil.

${ }^{4}$ Professora Doutora do Departamento de Química Analítica da Universidade Federal da Bahia, Salvador-Brasil.

${ }^{5}$ Professora Doutora do Departamento de Química Analítica da Universidade Federal da Bahia (veracancio@yahoo.com.br) Salvador-Brasil.

Recebido em: 08/09/2015 - Aprovado em: 14/11/2015 - Publicado em: 01/12/2015 DOI: http://dx.doi.org/10.18677/Enciclopedia_Biosfera_2015_093

\begin{abstract}
Dentre os estados do Nordeste, a Bahia destaca-se quanto à modernização do processo produtivo agropecuário, sendo a pecuária bovina essencial no agronegócio do Estado. Esta pesquisa objetivou avaliar as concentrações dos elementos químicos Mg, $\mathrm{P}, \mathrm{Fe}, \mathrm{Ca}, \mathrm{Mn}, \mathrm{Pb}$ e $\mathrm{Zn}$ em amostras de diferentes tecidos (músculo, fígado e rim) de bovinos comercializados na cidade de Salvador. Os bovinos tiveram as suas amostras coletadas em frigoríficos soteropolitanos com uma média de 18 exemplares por coleta, seis para cada tecido. Os elementos foram determinados por espectrometria de emissão óptica com plasma indutivamente acoplado (ICP OES). A ordem decrescente de concentração dos elementos em cada tecido foram as seguintes: músculo: $\mathrm{P}>\mathrm{Mg}>\mathrm{Ca}>\mathrm{Zn}>\mathrm{Fe}>\mathrm{Mn}>\mathrm{Pb}$; fígado: $\mathrm{P}>\mathrm{Mg}>\mathrm{Zn}>\mathrm{Ca}>\mathrm{Fe}>\mathrm{Pb}>\mathrm{Mn}$ e rim: $\mathrm{P}>\mathrm{Mg}>\mathrm{Ca}>\mathrm{Fe}>\mathrm{Zn}>\mathrm{Pb}>\mathrm{Mn}$. $\mathrm{O} \mathrm{Pb}$ apresentou valores abaixo do limite de detecção do método $\left(<0,050 \mathrm{mg} \cdot \mathrm{kg}^{-1}\right)$ para todos os tecidos de músculos. Entretanto, apresentou concentrações elevadas nos tecidos de fígado (3,71-7,24 mg. $\left.\mathrm{kg}^{-1}\right)$ e rim $\left(1,92-3,85 \mathrm{mg} \cdot \mathrm{kg}^{-1}\right)$. Os tecidos bovinos podem ser uma boa fonte de elementos químicos essenciais, principalmente, de $\mathrm{P}, \mathrm{Mg}$ e Fe. As concentrações de elementos que ficaram acima do limite estabelecido pela legislação brasileira foram as de $\mathrm{Zn}$ nas amostras de fígado e músculo, e as de $\mathrm{Pb}$ nas amostras de fígado e de rim.
\end{abstract}

RESUMO

PALAVRAS-CHAVE: bovinos, composição química, fígado, músculo, rim. 


\title{
ASSESSMENT OF CHEMICALS AND LEAD IN BOVINE TISSUES IN BAHIA, BRAZIL
}

\begin{abstract}
In the Northeast of Brazil, the modernization of the livestock industry of Bahia stands out. The cattle raising is also an essential part of the agribusiness of the state. This research aimed at evaluating the concentrations chemical elements such as: $\mathrm{Mg}, \mathrm{P}$, $\mathrm{Fe}, \mathrm{Ca}, \mathrm{Mn}, \mathrm{Zn}, \mathrm{Pb}$ in samples of different tissues (muscle, liver and kidney) of cattle marketed in the city of Salvador, Bahia. The cattle had their samples collected in butcher shops of the city of Salvador with an average of 18 copies per collection, six for each tissue. The elements were determined by Optical Emission Spectrometry with Inductively Coupled Plasma (ICP OES). The decreasing order of concentration of elements in each tissue were the following: muscle: $\mathrm{P}>\mathrm{Mg}>\mathrm{Ca}>\mathrm{Zn}>\mathrm{Fe}>\mathrm{Mn}>$ $\mathrm{Pb}$; Liver: $\mathrm{P}>\mathrm{Mg}>\mathrm{Zn}>\mathrm{Ca}>\mathrm{Fe}>\mathrm{Pb}>\mathrm{Mn}$ and kidney: $\mathrm{P}>\mathrm{Mg}>\mathrm{Ca}>\mathrm{Fe}>\mathrm{Zn}>\mathrm{Pb}>\mathrm{Mn}$. $\mathrm{Pb}$ showed values below the method detection limit $\left(<0.050 \mathrm{mg} \cdot \mathrm{kg}^{-1}\right)$ for all muscle tissues. However, it presented high concentrations in liver tissue $(3.71$ to $7.24 \mathrm{mg} . \mathrm{kg}$ ${ }^{1}$ ) and kidney (1.92 to $\left.3.85 \mathrm{mg} \cdot \mathrm{kg}^{-1}\right)$. The bovine tissue can be an excellent source of essential chemical elements, especially, $\mathrm{P}, \mathrm{Mg}$ and Fe. The concentrations of elements that were above the limit established by Brazilian legislation were $\mathrm{Zn}$ in samples of liver and muscle, and $\mathrm{Pb}$ in samples of liver and kidney.
\end{abstract}

KEYWORDS: cattle, chemical composition, liver, muscle, kidney.

\section{INTRODUÇÃO}

O comércio mundial de carne irá crescer em torno de $22 \%$ até 2023. É o que indica o relatório de projeções de longo prazo para a produção e demanda mundial divulgado pelo Departamento de Agricultura dos Estados Unidos (USDA). O Brasil é apontado como o principal exportador de carne bovina no período (BELLEI, 2014).

Dentre os estados do Nordeste, a Bahia apresenta os melhores resultados do ponto de vista da modernização do processo produtivo agropecuário. Nas duas últimas décadas, a diversificação e ampliação da produção ocorreram de maneira contundente e a Bahia, assume ainda, uma posição de liderança regional na modernização de sua cadeia de produção de carne bovina, detendo o "Certificado de Zona Livre da Febre Aftosa". Com isso, garante o seu acesso ao mercado internacional (CRUZ, 2011).

A pecuária bovina de corte é essencial no agronegócio do Estado da Bahia. A carne, em sentido amplo, é todo o tecido muscular de animais utilizado como alimento. Ela é caracterizada pela natureza das proteínas que a compõem, com a sua riqueza em aminoácidos essenciais, além de conter umidade, ácidos graxos essenciais, vitaminas, glicídios e sais minerais como elementos nutritivos complementares para o ser humano. É um alimento nobre devido à função plástica na formação de novos tecidos orgânicos, na produção de energia e na regulação dos processos fisiológicos, apresentando a biodisponibilidade de seus nutrientes. $\mathrm{O}$ conhecimento da composição dos alimentos consumidos no Brasil é imprescindível para garantir a segurança alimentar do país. Uma vez que, fornece elementos básicos para ações de orientação nutricional baseados em princípios de desenvolvimento local, diversificação da alimentação e desenvolvimento de novos produtos (TACO, 2011).

A Instrução Normativa $n^{\circ} 42$ do MAPA (BRASIL, 1999) indica procedimentos 
para as análises físico-químicas que devem ser empregados no controle de qualidade de produtos cárneos. Ela também traça o Plano de Controle de Resíduos (medicamentos, metais e agrotóxicos) em carnes, onde são apresentados laboratórios oficiais para receberem e executarem essas análises demandadas.

A poluição ambiental aliada às práticas tecnológicas como suplementos alimentares para animais e uso indiscriminado de produtos químicos como fertilizantes, fungicidas, inseticidas e herbicidas nas vegetações, é um motivo de preocupação, uma vez que esses produtos podem conter vários metais e suas aplicações podem aumentar a quantidade destes no solo e na água. A importância da produção animal no contexto global da atividade humana é indiscutível, influenciando a questão no fornecimento de alimentos, na segurança no trabalho, na geração de renda, assim como na conservação dos ecossistemas locais (DICK et al. 2015).

Várias pesquisas (MARÇAL et al., 2003; SOUZA et al., 2009; ROGGEMAN et al., 2013; CANTY et al., 2014) são realizadas focando a transferência de metais contaminantes presente no solo para os animais, tanto por meio de contaminação direta ou via vegetação com consequências impactantes na qualidade da carne bovina. Atualmente, a poluição do ambiente por metais pesados é um sério problema (ATSDR, 2011; OGUNDIRAN et al., 2012), o qual tem sido reconhecido em vários países do mundo.

O consumo, não só da carne bovina, mas também de suas vísceras, tem trazido apreensão para o meio científico. Isso, devido à importância do fígado e dos rins no metabolismo de metais traços e a vulnerabilidade desses órgãos para acumulação e toxicidade. De acordo com HARLIA et al., (2015), os metais pesados são passíveis de contaminação química para a carne bovina desde o nascimento do animal. Isto, devido evidentemente a contribuição de fatores ambientais.

Nesse mesmo raciocínio, outros pesquisadores avaliaram os possíveis efeitos da ação dos metais em bovinos. Eles levaram em consideração a idade, o sexo, a raça, o uso do habitat, a vegetação e, em sua totalidade, o meio ambiente. Os resultados desses estudos sugerem os riscos dessa exposição na saúde dos bovinos (ROGGEMAN et al., 2013; CANTY et al., 2014; ROGGEMAN et al., 2014;).

Este trabalho apresenta uma avaliação do teor de elementos químicos presentes na carne bovina consumida pela comunidade da região metropolitana da cidade de Salvador com o propósito de contribuir na segurança alimentar e na saúde comunitária. Para isso, os elementos químicos Mg, P, Fe, Ca, Mn, Zn e Pb, foram investigados em amostras de carne bovina coletadas na cidade de Salvador.

\section{MATERIAL E MÉTODOS}

\section{Coleta e preparo das amostras}

Foram coletadas 18 amostras, in natura, de músculo, rim e fígado de bovinos (06 de cada tecido) durante o período de abril a junho de 2008, em quatro frigoríficos de Salvador, Bahia. As amostras foram armazenadas em sacos de polietileno e encaminhadas ao laboratório sob-resfriamento. Todos os materiais, a exemplo de sacos de polietileno, vidrarias e demais utensílios utilizados nas análises foram previamente lavados (Extran $0,5 \%$ por $24 \mathrm{~h}$ ) e descontaminados $\left(\mathrm{HNO}_{3} \quad 10 \%\right.$ por $24 \mathrm{~h}$ ), enxaguados três vezes com água destilada, e por fim, uma única vez, com água ultrapura MILLI-Q®, sendo armazenados em ambiente isento de poeira.

As amostras descongeladas foram cortadas, trituradas e homogeneizadas. 
Em seguida, cerca de $20 \mathrm{~g}$ da amostra foram desidratadas em placas de Petri (estufa de ventilação a $105^{\circ} \mathrm{C}$ por 72 horas), homogeneizadas, tamisadas (partículas $149 \mu \mathrm{m}, 100 \mathrm{mesh}$ ), quarteadas e armazenadas em frascos de vidro.

\section{Digestão das amostras}

Para a digestão, cerca de $1,0 \mathrm{~g}$ da amostra desidratada foi digerido em bloco digestor com $3 \mathrm{~mL}$ de $\mathrm{H}_{2} \mathrm{SO}_{4}$ e $2 \mathrm{~mL}$ de $\mathrm{HNO}_{3}$, ambos os ácidos concentrados. A digestão teve duas rampas de aquecimento: $100^{\circ} \mathrm{C}$ por 20 minutos e $240^{\circ} \mathrm{C}$ por 60 minutos. Em seguida, adicionou-se $5 \mathrm{~mL}$ de $\mathrm{H}_{2} \mathrm{O}_{2} 30 \%$. A mistura permaneceu em aquecimento até ficar completamente límpida e transparente com redução do volume para cerca de $5 \mathrm{~mL}$. Após resfriada, as amostras digeridas foram avolumadas, em balões volumétricos, para 10,00 mL com água ultrapura MILLI-Q®.

\section{Acurácia e determinação analítica}

Em cada batelada de digestão das amostras foram realizadas três provas em branco. A validação do método desenvolvido para o tratamento e digestão das amostras foi realizada utilizando o padrão de referência de fígado bovino National Institute of Standards \& Techonogy - NIST/SRM-1577b, introduzida nas análises de forma aleatória.

Todas as soluções necessárias às determinações foram preparadas com reagentes de grau analítico (Merck) e água ultrapura MILLI-Q®. O preparo das soluções padrões da curva analítica necessária à determinação dos elementos foi a partir das soluções estoque contendo $1000 \mathrm{mg} \cdot \mathrm{L}^{-1}$ de $\mathrm{Mg}, \mathrm{P}, \mathrm{Fe}, \mathrm{Ca}, \mathrm{Mn}, \mathrm{Pb}$ e Zn.

As determinações dos elementos químicos foram realizadas por espectrometria de emissão óptica com plasma indutivamente acoplado (ICP OES), que é uma fonte espectrométrica de emissão utilizada para a determinação de traços de metais em matrizes alimentícias e outros materiais (HOLLER et al., 2014). Foram utilizadas as seguintes linhas espectrais (nm), Mg, 285,209 (I); P, 177,434 (I); Fe, 238,203 (II); Ca, 396,847 (II); Mn, 257,611 (I); Pb, 220,353(II); Zn, 213,857 (I), sendo I linha de emissão atômica e II linha de emissão iônica. Foram obtidas as estimativas dos limites de detecção (LOD) e de quantificação (LOQ) para cada elemento investigado, considerando o desvio padrão relativo das intensidades de 10 ensaios do branco analítico.

\section{Análise estatística}

Todos os resultados foram reportados como média \pm 0 desvio padrão. Os dados foram analisados segundo a sua normalidade e homocedasticidade por meios dos testes de Kolmogorov-Smirnov e Barlett, respectivamente.

A determinação da significância estatística da diferença entre as variâncias foi por meio da Análise de Variância (ANOVA) seguida do teste de Tukey para os dados paramétricos ou; pelo teste de Kruskal-Wallis seguido do teste de Mann-Whitney, quando os dados foram não paramétricos. A análise de correlação entre os pares de elementos foi por meio da Correlação de Spearman. Todas as análises foram realizadas utilizando o software SPSS 20.0 e considerando os níveis de probabilidade $p<0,01$ e $p<0,05$. 


\section{RESULTADOS E DISCUSSÃO}

\section{Concentrações dos elementos químicos nos tecidos}

As concentrações dos elementos químicos de cada amostra, nos diferentes tecidos bovinos investigados, estão relacionadas na Tabela 1. Foi observado que para todos os elementos investigados, as amostras para um mesmo tecido, variaram de formas significativas as suas concentrações.

A ordem decrescente de concentração dos elementos em cada tecido foi: para o músculo: $\mathrm{P}>\mathrm{Mg}>\mathrm{Ca}>\mathrm{Zn}>\mathrm{Fe}>\mathrm{Mn}>\mathrm{Pb}$; fígado: $\mathrm{P}>\mathrm{Mg}>\mathrm{Zn}>\mathrm{Ca}>\mathrm{Fe}>\mathrm{Pb}>\mathrm{Mn}$ e rim: $\mathrm{P}>\mathrm{Mg}>\mathrm{Ca}>\mathrm{Fe}>\mathrm{Zn}>\mathrm{Pb}>\mathrm{Mn}$. Assim, o $\mathrm{P}$ e Mg, foram majoritários em todos os tecidos, seguidos do $\mathrm{Ca}$ ou do $\mathrm{Zn}$. A carne bovina contém concentrações elevadas de elementos como $\mathrm{Mg}$, $\mathrm{Ca}$, Fe e $\mathrm{Zn}$ em uma forma disponível (CARAPELLI, 2011).

A concentração de $P$ das amostras variou de 3,27 a $10,83 \mathrm{~g} \cdot \mathrm{kg}^{-1}$, sendo valores mais elevados do que os reportados na Tabela Brasileira de Composição dos Alimentos elaborada pelo Núcleo de Estudos e Pesquisas em Alimentação da Universidade Estadual de Campinas, NEPA/Unicamp (TACO, 2011) e por outras investigações científicas (MITIC et al., 2012; CHEN et al., 2013). Por outro lado, CAMARGO et al, 2008 encontraram a concentração de $18,93 \mathrm{~g} \cdot \mathrm{kg}^{-1}$, valor muito superior aos aqui reportados. O P é muito ativo metabolicamente, estando distribuído por todas as células do organismo e no fluido extracelular, possuindo numerosas funções importantes no organismo, principalmente, no metabolismo energético (MAHAN et al., 1998). Ele é um dos elementos que devem ser suplementados para o rebanho, sendo adicionado como constituinte de fertilizantes nas pastagens (TEIXEIRA et al., 2011).

$\mathrm{O} \mathrm{Mg}$ apresentou concentrações que variaram de 0,36 a $0,61 \mathrm{~g} \cdot \mathrm{kg}^{-1}$. O valor médio de Mg observado neste estudo em músculo bovino foi superior aos teores encontrados na TACO (2011), onde encontraram o valor de $200 \mathrm{mg} \cdot \mathrm{kg}^{-1}$. Entretanto, - United States Department of Agriculture (USDA, 2001) reportou concentração menor de $\mathrm{Mg}$ em rim bovino. O Mg é um cátion intracelular extremamente importante para os organismos vivos. No organismo humano adulto há, aproximadamente, 20 a $28 \mathrm{~g}$ de $\mathrm{Mg}$, das quais $60 \%$ encontram-se nos ossos, $26 \%$ nos músculos e o restante nos tecidos moles e líquidos corpóreos (MAHAN et al., 1998). Este elemento tem sido investigado com relação a patologias como eclampsia, alcoolismo, doenças cardíacas, aterosclerose, asma e hipertensão (COZZOLINO, 2005).

$\mathrm{O}$ teor de $\mathrm{Ca}$ das amostras analisadas variou de 109 a $479 \mathrm{mg} \cdot \mathrm{kg}^{-1}$. Em estudo realizado pela USDA (2001), e BLANCO-PENEDO et al. (2006) avaliando o teor de $\mathrm{Ca}$ em rim bovino foram observados teores inferiores aos encontrados neste estudo. O Ca ocupa uma posição central entre as substâncias minerais do organismo tanto quantitativamente como por sua distribuição universal, sendo encontrado no esqueleto e em outros tecidos. Esse metal tem importância para o homem nas atividades enzimáticas, por exemplo, ele é necessário para a ação de algumas enzimas ( $\mathrm{Ca}^{2+}$ ATPase) e pode competir com o Fe no sítio de ligação, ou então ser absorvido pela célula (BERG et al., 2004). 
TABELA 1. Concentração dos elementos químicos $\left(\mathrm{mg} \cdot \mathrm{kg}^{-1}\right)$ em amostras de tecidos bovinos comercializados no Estado da Bahia, Brasil.

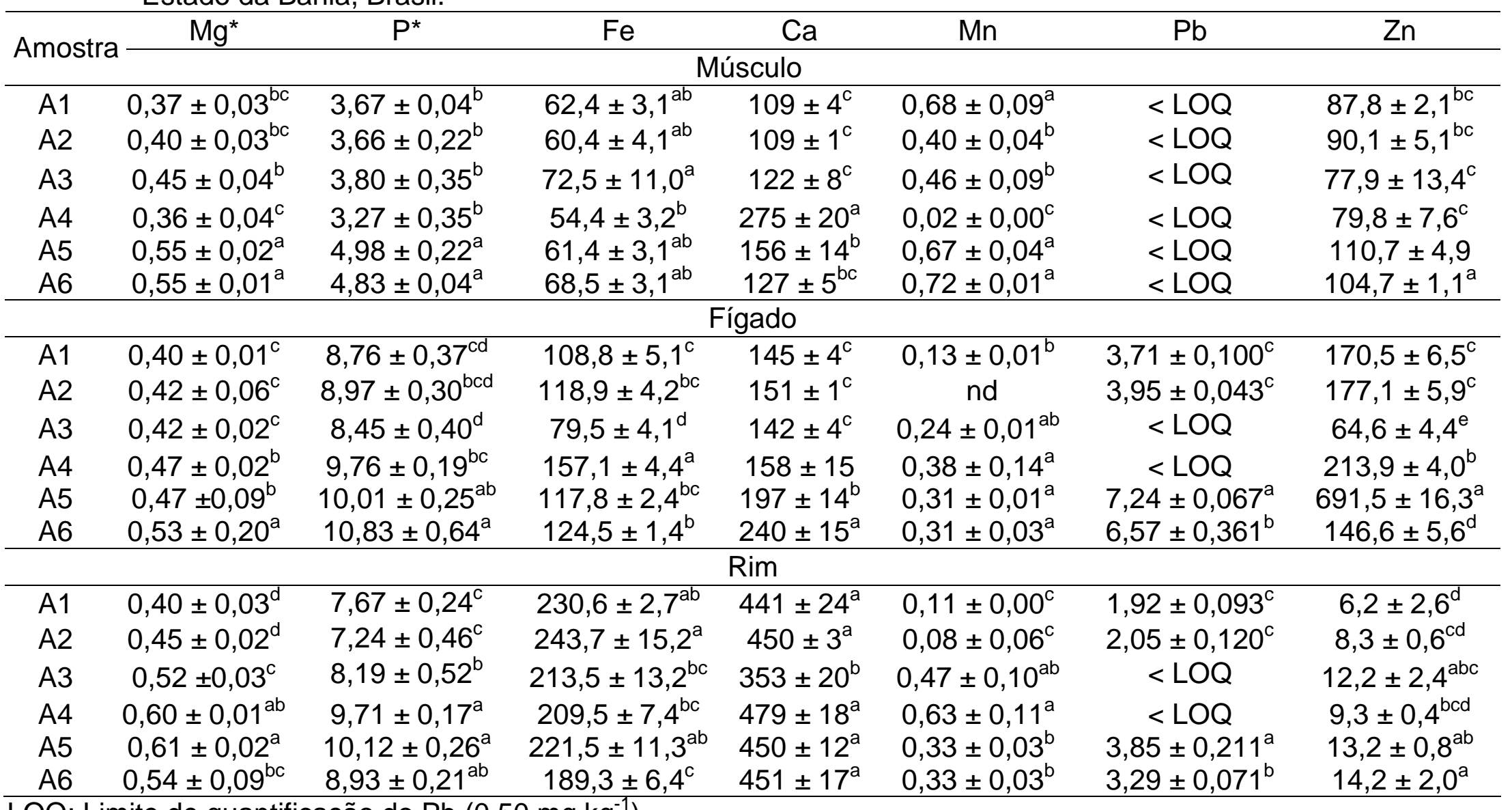

LOQ: Limite de quantificação do $\mathrm{Pb}\left(0,50 \mathrm{mg} \cdot \mathrm{kg}^{-1}\right)$.

Valores com letras diferentes (a,b,c,d,e) para o mesmo tecido e coluna, apresentaram diferenças significativamente a nível de $p<0,05$.

* Valores em g. $\mathrm{kg}^{-1}$.

nd: não determinado. 
As concentrações encontradas para o $\mathrm{Mn}$ foram entre 0,13 a $0,68 \mathrm{mg} \cdot \mathrm{kg}^{-1}$. As concentrações reportadas em outras pesquisas com $\mathrm{o} \mathrm{Mn}$ em tecidos bovinos variaram bastante, havendo pesquisas que encontraram valores inferiores (DEMIREZEN \& URUÇ, 2006) e superiores (CAMARGO et al., 2008) aos encontrados nas amostras aqui investigadas. O Mn é um microelemento essencial encontrado, no ser humano, principalmente nos ossos. O Mn é um componente de várias enzimas, inclusive glutamina sintetase, piruvato carboxilase e superóxido dismutase mitocondrial. Ele está associado à formação de tecido conjuntivo, ósseo, ao crescimento, a reprodução e ao metabolismo de carboidratos e lipídeos (COZZOLINO, 2005).

O Zn apresentou uma concentração que variou de 6,2 a $691,5 \mathrm{mg} \cdot \mathrm{kg}^{-1}$. Concentrações menores que as encontradas nesta pesquisa foram reportadas na literatura para o músculo (IWEGBUE' 2011), o rim (ROGGEMAN et al., 2014) e fígado (PINHEIRO et al., 2011). Entretanto, CAMARGO et al. (2008) observaram valores maiores no músculo bovino. Esse elemento é o segundo elemento traço mais abundante no corpo humano, sendo $80 \%$ distribuído em ossos, músculos, fígado e pele, sendo um elemento essencial ao metabolismo humano, participando da atividade de diversas enzimas, assim como na síntese e degradação dos carboidratos, lipídeos, proteínas e ácidos nucléicos (COZZOLINO, 2005).

O Fe apresentou concentrações que variaram 54,4 a 243,7 mg. $\mathrm{kg}^{-1}$, sendo encontradas concentrações no rim de até 4,5 vezes maior do que as encontradas nos músculos. Concentrações maiores, foram encontradas por MITIC et al. (2012) e PRETORIUS et al. (2015), que reportaram os valores de 88,6-121,5; 104,7 \pm 2 ,2 e 20,4-24,5 mg. $\mathrm{kg}^{-1}$ de $\mathrm{Fe}$ no músculo bovino. Entretanto, foram similares às concentrações apresentadas na TCBA, (2006), para os músculos $(67,8$ - 94,4 mg. $\left.\mathrm{kg}^{-1}\right)$. O Fe é um elemento essencial e cerca de dois bilhões de pessoas no mundo têm sua carência (PRETORIUS et al., 2015), isso por que o Fe presente nos alimentos não são completamente biodisponíveis. A sua absorção se torna mais efetiva quando ligados ao anel porfirínico de proteínas (CARAPELLI, 2011). Dessa forma, é esperado que uma quantidade do Fe, ingerido pelo animal, seja eliminada, seguindo a rota metabólica para a sua excreção e, consequentemente, se encontrar maiores concentrações no seu fígado e nos rins.

$\mathrm{O} \mathrm{Pb}$ apresentou valores abaixo do limite de detecção do método $(<0,050$ $\mathrm{mg} . \mathrm{kg}^{-1}$ ) para todos os tecidos de músculos. Entretanto, apresentou concentrações elevadas nos tecidos de fígado $\left(3,71-7,24 \mathrm{mg} \cdot \mathrm{kg}^{-1}\right)$ e rim $\left(1,92-3,85 \mathrm{mg} \cdot \mathrm{kg}^{-1}\right)$. Dessa forma, as concentrações no rim foram até cerca de duas vezes maior que as encontradas nas amostras de tecido do fígado. CANTY et al. (2014) e ROGGEMAN et al. (2014) também encontraram $\mathrm{Pb}$ em tecidos de rim bovino, entretanto, foram concentrações cerca de dez a vinte vezes menores do que as encontradas nas amostras de rim desta pesquisa. Por outro lado, KHALAFALLA et al. (2011) encontraram valores de contaminação por chumbo em tecidos de rim e fígado bovinos maiores que as aqui encontradas. Esse elemento é classificado como a segunda substância mais tóxica pela Agência de Substâncias Tóxicas e Registro de Doenças (ATDSR, 2011), não possuindo nenhuma função biológica conhecida. No meio ambiente, ele pode se bioacumular em plantas (SILVA, et al., 2015) que o gado se alimenta. O seu efeito tóxico sobre a saúde animal pode ser controlado, em parte, pelo mecanismo de desintoxicação (ROGGEMAN et al., 2014) que envolve a ligação desse metal com metalotioneinas presentes no fígado e no rim (NORDBERG et al., 1994). A exposição a altas concentrações de $\mathrm{Pb}$ pode produzir consequências 
severas, como lesão cerebral, cólica intestinal, paralisias, anemia e morte (MAHAN et al., 1998). Uma vez absorvido o $\mathrm{Pb}$ passa à corrente sanguínea e, mais de $95 \%$ desse elemento, liga-se aos eritrócitos, causando aumento da fragilidade e redução do tempo de vida das células (BERG et al. 2004).

A presença de $\mathrm{Pb}$ nas amostras de tecidos de fígado e rim das amostras investigadas sugerem que o animal, provavelmente, estava exposto à alguma dessas fontes de contaminação ambiental, tendendo a bioacumular esse contaminante no fígado e rins. Uma vez que boa parte da população tem hábitos alimentares que incluem essas vísceras, elas se tornam uma significativa fonte de contaminação humana.

\section{Ordem de distribuição entre os tecidos e Correlações}

Os elementos $\mathrm{Fe}, \mathrm{Ca}$ e $\mathrm{Mg}$ tenderam a se bioconcentrar no rim, enquanto o $\mathrm{P}$ e $\circ \mathrm{Mn}$ estavam em maior concentração no músculo. Somente o $\mathrm{Zn}$ e $\circ \mathrm{Pb}$ apresentaram maiores concentrações no fígado, sendo que o $\mathrm{Pb}$ se distribui de maneira igual no fígado e rim (Tabela 2). As concentrações de $\mathrm{Pb}$ foram mais altas nos tecidos do fígado do que no rim, o contrário foi observado por ROGGEMAN et al. (2014).

TABELA 2. Concentração média (mg. $\mathrm{kg}^{-1}$ ) dos elementos químicos em amostras de tecidos bovinos comercializados no Estado da Bahia, Brasil.

\begin{tabular}{ccccc}
\hline Tecido & Músculo & Fígado & Rim & Ordem de distribuição \\
\hline $\mathrm{Fe}$ & $63,3 \pm 6,4^{\mathrm{c}}$ & $117,8 \pm 25,0^{\mathrm{b}}$ & $218 \pm 18,7^{\mathrm{a}}$ & Rim > Fígado $>$ Músculo \\
$\mathrm{Ca}$ & $149,5 \pm 64^{\mathrm{a}}$ & $172,1 \pm 39^{\mathrm{a}}$ & $437,5 \pm 43^{\mathrm{b}}$ & Rim > Fígado = Músculo \\
$\mathrm{P}^{*}$ & $4,03 \pm 0,70^{\mathrm{a}}$ & $9,46 \pm 0,9^{\mathrm{b}}$ & $8,56 \pm 1,24^{\mathrm{b}}$ & Músculo > Rim = Fí́gado \\
$\mathrm{Mg}^{*}$ & $0,45 \pm 0,09^{\mathrm{a}}$ & $0,45 \pm 0,05^{\mathrm{a}}$ & $0,52 \pm 0,08^{\mathrm{a}}$ & Rim > Fígado = Músculo \\
$\mathrm{Mn}$ & $0,49 \pm 0,27^{\mathrm{a}}$ & $0,28 \pm 0,09^{\mathrm{a}}$ & $0,33 \pm 0,21^{\mathrm{a}}$ & Músculo > Rim > Fígado \\
$\mathrm{Pb}$ & $<\mathrm{LOQ}$ & $3,65 \pm 3,00^{\mathrm{b}}$ & $1,91 \pm 1,53^{\mathrm{b}}$ & Fígado = Rim > Músculo \\
$\mathrm{Zn}$ & $91,8 \pm 13,3^{\mathrm{c}}$ & $244,0 \pm 1,53^{\mathrm{a}}$ & $10,6 \pm 3,1^{\mathrm{b}}$ & Fígado $>$ Músculo $>$ Rim \\
\hline
\end{tabular}

Valores com letras diferentes, para a mesma linha apresentaram diferenças significativamente a nível de $p<0,05$.

* Valores em g.kg ${ }^{-1}$.

A correlação entre pares de elementos apresentou diferentes tendências entre os tecidos (Tabela 3). No músculo, foram observadas correlações fortes envolvendo o $\mathrm{Zn}$ e o $\mathrm{P}$, com destaque para os pares: $\mathrm{P}-\mathrm{Mg}(r=0,917), \mathrm{P}-\mathrm{Zn}(\mathrm{r}=$ $0,907)$ e $\mathrm{Mg}-\mathrm{Zn}(\mathrm{r}=0,800)$. No fígado as correlações mais fortes envolveram o $\mathrm{Ca} \mathrm{e}$ o P, tais como: Ca-P $(r=0,914), P-M g(r=0,891), M g-M n(r=0,842)$. No rim, as correlações foram menos fortes do que as observadas no músculo e no fígado, havendo maiores correlações entre pares elementares que envolviam o P (P-Mn, $r=$ $0,961), \mathrm{Zn}(\mathrm{Zn}-\mathrm{P}, \mathrm{r}=0,679)$ e o $\mathrm{Mn}(\mathrm{Mn}-\mathrm{Mg}, \mathrm{r}=0,695)$. 
TABELA 3. Análise de correlação entre os elementos químicos nos tecidos investigados.

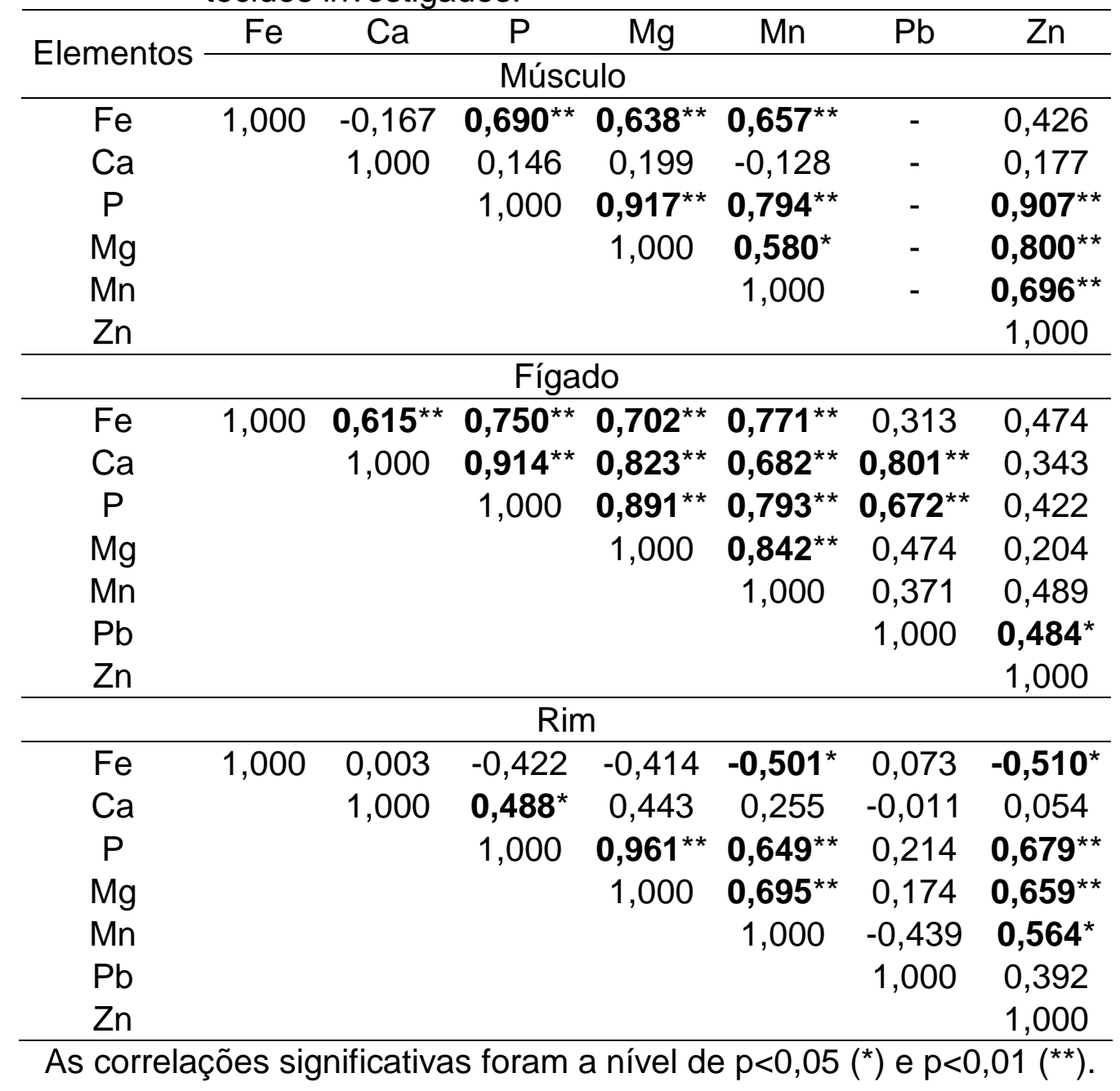

Estudos na literatura que reportem correlações entre pares de elementos químicos em tecidos de bovino são incipientes, sendo mais frequentes em estudos de outros alimentos cárneos, principalmente, peixes. Em músculo de peixes observou-se a mesma tendência para o $\mathrm{Zn}$ apresentar maior e mais fortes correlações com os outros elementos (VIANA et al., 2012).

\section{Avaliação de riscos à saúde humana}

No Brasil, a Agência de Vigilância Sanitária (ANVISA), em seu decreto $n^{\circ}$ 55.871 de 1965 e o Ministério da Saúde, pela Portaria 685-98 (BRASIL, 1998) estabeleceram valores limítrofes permitidos em alimentos para diversos elementos químicos. Entre os elementos aqui investigados, apenas o $\mathrm{Zn}$ e $\mathrm{Pb}$ possuem limítrofes estabelecidos por essas legislações, sendo 50,0 e 2,0 mg. $\mathrm{kg}^{-1}$ (peso úmido), respectivamente.

Dessa forma, as concentrações de $Z n$ encontradas nos músculos e fígado, considerando a sua conversão para peso úmido, estão acima dos limites estabelecidos pela Agência Nacional de Vigilância Sanitária. Essas concentrações, nos músculos, ultrapassam de cinco à sete vezes o valor limite.

Para $\circ \mathrm{Pb}$, somente os músculos apresentaram valores abaixo do limite estabelecido pela legislação brasileira. No fígado e rim as concentrações superaram 
cerca de três a doze vezes o seu valor limítrofe.

Além dessas normativas, para o Plano Nacional de Controle de Resíduos Contaminantes (PNCRC), as concentrações de chumbo em tecidos de rim bovino não deve ultrapassar $0,5 \mathrm{mg} \cdot \mathrm{kg}^{-1}$ (BRASIL, 1979). Dessa forma, os tecidos de rim investigados estavam acima do limite estabelecido pela legislação brasileira. A legislação brasileira não reporta valores limítrofes para o fígado, mas, as concentrações de $\mathrm{Pb}$ encontradas nesse tecido também foram superiores aos limites estabelecidos para o rim.

\section{CONCLUSÕES}

Em geral, os elementos investigados tenderam a se bioconcentrar no rim ou no músculo, havendo fortes correlações entre pares de elementos envolvendo, principalmente, $\mathrm{o} \mathrm{Zn}$ e $\mathrm{o} \mathrm{P}$. Os tecidos investigados são fontes alimentares significativas para os elementos químicos $\mathrm{P}, \mathrm{Mg}$ e Fe. Entretanto, as concentrações do $\mathrm{Zn}$, no músculo e fígado, e do $\mathrm{Pb}$, no fígado e músculo, apresentaram concentrações acima do limite estabelecido pela legislação brasileira.

\section{REFERÊNCIAS}

ANVISA. Agência Nacional de Vigilância Sanitária. Decreto $\mathrm{n}^{\circ}$ 55871, de 26 de março de 1965.10 Disponível <http://www.anvisa.gov.br/legis/decretos/55871_65.htm>. Acesso em: 15 ago. 2014.

ATSDR. Agency for Toxic Substances and Disease Registry. The 2011 priority list of hazardous substances. Disponível em: <http://www.atsdr.cdc.gov/SPL/index.html>. Acesso em: 15 mar. 2014.

BELLEI, F. USDA: Comércio mundial de carnes deve crescer $22 \%$ até 2023. Notícias Agrícolas, São Paulo, 20 fev. 2014. Disponível em: <http://www.noticiasagricolas.com.br/noticias/carnes >. Acesso em: 24 jul. 2015.

BERG, J. M.; TYMOCZKO, J. L.; STYER, L. Bioquímica. Rio de Janeiro: Guanabara Koogan, 2004, 1059 p.

BLANCO-PENEDO, I.; CRUZ, J. M.; LÓPEZ-ALONSO, M.; MIRANDA, M.; CASTILLO, C.; HERNÁNDEZ, J.; BENEDITO, J. L. Influence of copper status on the accumulation of toxic and essential metals in cattle. Environment International, v.32, p. 901-906, 2006.

BRASIL. Ministério da Agricultura, Pecuária e Abastecimento. Portaria n 86, de 26 de Janeiro de 1979. Programa Nacional de Controle de Resíduos Biológicos em Carnes. Diário Oficial da União, Brasília, DF, p. 1913, 07 fev. 1979. Seção 1.

BRASIL. Ministério da Agricultura, Pecuária e Abastecimento. Instrução Normativa no 20, de 21 de julho de 1999. Oficializa os métodos analíticos físico-químicos, para controle de produtos cárneos e seus Ingredientes. Diário Oficial da União, Brasília, DF, p. 2, 05 jan. 2009. Seção 1.

BRASIL. Ministério da Saúde. Portaria $n^{\circ} 685$, de 27 de agosto de 1998. Aprova o 
Regulamento Técnico: "Princípios Gerais para o Estabelecimento de Níveis Máximos de Contaminantes Químicos em Alimentos" e seu anexo: "Limites Máximos de tolerância para contaminantes inorgânicos". Parcialmente revogada pela Resolução - RDC n. 42, de 29/08/2013. Disponível em: <http://s.anvisa.gov.br/wps/s/r/blNk>. Acesso em: 16 jul. 2014

CAMARGO, A. M.; RODRIGUES, V. C.; RAMOS, K. C. B. T.; OLIVEIRA, E. C. D. de; MEDEIROS, L. F. D. Composição mineral da carne de bovinos de diferentes grupos genéticos com idades distintas. Revista Brasileira de Saúde e Produção Animal, v.9, n.3, p.578-584, jul./Set., 2008.

CANTY, M.J.; SCANLON, A.; COLLINS, D. M.; MCGRATH, G.; CLEGG, T.A.; LANE, E.; SHERIDAN, M. K.; MORE, S. J. Cadmium and other heavy metal concentrations in bovine kidneys in the Republic of Ireland. Science of the Total Environment, v.485-486, p.223-231, 2014.

CARAPELLI, R. Desenvolvimento de métodos para fracionamento de proteínas e metaloproteínas em carne bovina. São Carlos: UFSCar, 2012. 79 p.

CHEN, S., LIN, Y.; KAO, Y.; SHIH, Y. Trace elements and heavy metals in poultry and livestock meat in Taiwan. Food Additives \& Contaminants: Part B, v. 6, n. 4, p. 231-236, 2013.

COZZOLINO, S. M. F. Biodisponibilidade de Nutrientes. Barueri, São Paulo: Manole, 2005. 878 p.

CRUZ, A. C. Pecuária bovina de corte: desenvolvimento e desafios para o Estado da Bahia. Cairu em Revista, ano 01, Out 2011.

DEMIREZEN, D.; URUÇ, K. Comparative study of trace elements in certain fish, meat and meat products. Meat Science, v. 74, p. 255-260, 2006.

DICK, M.; SILVA, M.A.; DEWES, H. Life cycle assessment of beef cattle production in two typical grassland systems of southern Brazil. Journal of Cleaner Production, v.96, p.426-434, 2015.

HARLIA, E.; SURYANINGSIH, L.; SURYANTO, D.; ISTIQOMAH, H.; KOMARIAH, R.W. Safety Study of Milled Beef and Slices Beef Jerky Viewed from Cadmium and Plumbum Heavy Metals Contamination. The First International Symposium on Food and Agro-biodiversity (ISFA2014). Procedia Food Science, v.3, p. 409-412, 2015.

HOLLER, F. J.; SKOOG, D. A.; WEST, D. M. Fundamentos de Química Analítica. São Paulo: Cengage learning, 2014. 955 p.

IWEGBUE, C. M. A. Trace metal contents in some brands of canned beef in Nigeria. Toxicological \& Environmental Chemistry, v.93, n.7, 2011.

KHALAFALLA, F. A.; ALI, F. H.; SCHWAGELE, F.; ABD-EL-WAHAB, M. A. Heavy metal residues in beef carcasses in Beni-Suef abattoir, Egypt. Veterinaria Italiana, 
v.47, n.3, 351-361, 2011.

MAHAN, L. K.; ESCOTT-STUMP, S. KRAUSE: Alimentos, Nutrição e Dietoterápica. São Paulo: Ed. Roca, 1988. 207p.

MARÇAL, W. S.; VILLEGAS-NAVARRO, A.; NASCIMENTO, M. R. L.; GUERRA, A. P.; FUJIHARA, C. J.; BRUSCHI, A. B. M. Bovinos e eqüinos como bioindicadores da poluição ambiental. Revista Brasileira Ciências Veterinária, v. 10, n. 1, p. 16-20, jan./abr. 2003

MITIC, S. S., STOJKOVIC, M. B., PAVLOVIC, A. N., TOSIC, S. B., MITIC, M. N. Heavy metal content in different types of smoked meat in Serbia. Food Additives and Contaminants: Part B, v.. 5, n. 4, p. 241-245, Dec. 2012.

NORDBERG GF, JIN T, NORDBERG M. Subcellular targets of cadmium nephrotoxicity: cadmium binding to renal membrane proteins in animal with or without protective metallothionein synthesis. Environmental Health Perspect, v.102, n.3, p.191-194, 1994.

OGUNDIRAN, M.B.; OGUNDELE, D.T.; AFOLAYAN, P.G.; OSIBANJO, O. Heavy metals levels in forage grasses, leachate and lactating cows reared around lead slag dumpsites in Nigeria. International Journal of Environmental Research, v.6, n.3, p.695-702, 2012.

PINHEIRO, C. P., BOMJARDIM, H. A., ANDRADE, S. J. T., FAIAL, K. C. F., OLIVEIRA, C. M. C., BARBOSA, J. D. Níveis de fósforo, cobre, cobalto e zinco em bubalinos (Bubalus bubalis) na llha de Marajó, Estado do Pará. Pesquisa Veterinaria Brasileira, v.31 n.3, Rio de Janeiro, Mar. 2011.

PRETORIUS, B., SCHÖNFELDT, H. C., HALL, N. Total and haem iron content lean meat cuts and the contribution to the diet. Food Chemistry, [online]. DOI: http://dx.doi.org/10.1016/j.foodchem.2015.02.109. 2015.

ROGGEMAN, S.; DE BOECK, G.; DE COCK, H.; BLUST, R.; BERVOETS, L. Accumulation and detoxification of metals and arsenic in tissues of cattle (Bos taurus), and the risks for human consumption. Science of the Total Environment, v.466-467, p.175-184, 2014.

ROGGEMAN, S.; VAN DEN BRINK ,N.; VAN PRAET, N.; BLUST, R.; BERVOETS, L. Metal exposure and accumulation patterns in free-range cows (Bos taurus) in a contaminated natural area: Influence of spatial and social behavior. Environmental Pollution, v.172, p.186 -199, 2013.

SILVA, E.; SANTOS, P. S.; GUILHERME, M. F. S. Lead in plants: a brief review of its effects, mechanisms toxicological and remediation. Agrarian Academy, v.2, n.3, p. 1-20, 2015.

SOUZA, M. V.; VIANNA, M. W. S.; ZANDIM, B. M.; FERNANDES, R. B. A.; FONTES, M. P. F. Metais pesados em amostras biológicas de bovinos. Ciência 
Rural, v. 39, n. 6, p.1774-1781, 2009.

TACO. Tabela Brasileira de Composição de Alimentos. Núcleo de Estudos e Pesquisas, NEPA. Universidade Estadual de Campinas, UNICAMP, 4.ed.rev. e ampl. Campinas: TACO-UNICAMP, 2011. 161p. Disponível em: <http://www.unicamp.br/nepa/taco>. Acesso em: 11 jun. 2014

TEIXEIRA, S., BRANCO, A. F., GRANZOTTO, F., BARRETO, J. C., ROMA, C. F. C., CASTAÑEDA, R. D. Fontes de fósforo em suplementos minerais para bovinos de corte em pastagem de Cynodon nlemfuensis Vanderyst. Revista Brasileira de Zootecnia, Viçosa, v. 40, n. 1, p. 190-199, 2011.

USDA - United State Departament of Agricultura / Nutrient Database for Standard Reference, 2001. Disponível em: <http://ndb.nal.usda.gov/>. Acesso em 05 jun. 2014

VIANA, Z. C. V., SILVA, E., FERNANDES, G. B., KORN, M. G. A., SANTOS, V. L. C. $\mathrm{S}$. Estudo da absorção de elementos químicos no músculo de peixes do litoral da Bahia. Revista de Ciências Médicas e Biológicas, v.11, n.1, p.27-34, 2012. 